\title{
Gastric carcinosarcoma with rhabdomyosarcomatous differentiation: a case report and literature review
}

\author{
Hsing-Yu Shih ${ }^{1}$, Che-Pin Lin ${ }^{2}$, Feng-Chuan Tai ${ }^{3 *}$
}

\begin{abstract}
${ }^{1}$ Department of Surgery, Cathay General Hospital, Taipei, Taiwan.
${ }^{2}$ Division of hematology and oncology, Cathay General Hospital, Taipei, Taiwan.

${ }^{3}$ Division of General Surgery, Cathay General Hospital, Taipei, Taiwan.
\end{abstract}

\section{To Cite}

Shih H-Y, Lin C-P, Tai F-C. Gastric carcinosarcoma with rhabdomyosarcomatous differentiation: a case report and literature review. J Gastric Surg 2020; 2(4).

\section{Publication history}

Received: November 13, 2020

Accepted: November 19, 2020

Article in press: November 22, 2020

Published online: November 24, 2020

\section{*Correspondence to}

Feng-Chuan Tai, MD

Division of General Surgery

Cathay General Hospital,

280 Renai Rd. Sec.4, Taipei, Taiwan

cghsurgery@gmail.com

Telephone: +886-0931099299

Fax: $+886-27540222$

\begin{abstract}
Gastric carcinosarcoma with rhabdomyosarcomatous differentiation is a rare tumor. Herein, we report the case of a 34-year-old man with a history of dysphagia, upper abdominal fullness, and poor appetite. Endoscopic findings showed a large friable mass that originated from the gastric cardia and lesser curvature of the high body. Consequently, radical total gastrectomy with Roux-en-Y esophagojejunostomy was performed. Histopathological analysis of the resected specimen revealed that the mass had invaded the serosa without regional lymph node metastasis; moreover, the tumor was positive for desmin and myogenin. Finally, we conclude this report with literature review and discussion.
\end{abstract}

Key Words:

Gastric tumor, gastric carcinosarcoma, rhabdomyosarcomatous. 


\section{Background}

Carcinosarcoma is an uncommon biphasic malignant tumor composed of carcinoma and sarcoma components. In the upper gastrointestinal tract, carcinosarcoma is more frequently found in the esophagus; however, its gastric localization has been reported rarely.[13] The presentation of gastric carcinosarcoma with rhabdomyosarcomatous differentiation is even rarer, with only 12 cases reported thus far.[4-15]

Herein, we report the case of a male patient who developed gastric carcinosarcoma with rhabdomyosarcomatous differentiation and provide the clinical and histopathological features of this tumor. Moreover, we also review and discuss relevant literature.

\section{Case report}

A 34-year-old man had been experiencing dysphagia along with upper abdomen fullness and poor appetite for 2 months; he had lost $12 \mathrm{~kg}$ of body weight over the previous 6 weeks. Initially, he went visited a local clinic, where panendoscopy was performed; the results revealed a large (size, $4 \mathrm{~cm}$ ) friable tumor, stretching from the cardia to the lesser curvature side of the high body (Figure 1). The tumor arose from the submucosal layer with infiltration to the mucosal layer. A biopsy sample was obtained and sent for pathological examination. The histopathological analysis confirmed the presence of malignancy with rhabdomyosarcomatous differentiation.

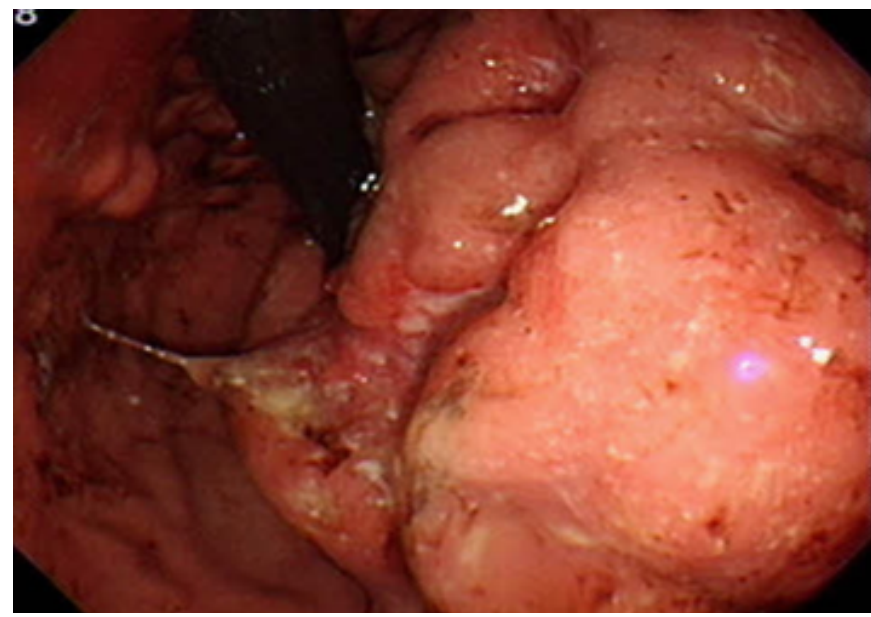

Figure 1: Panendoscopy revealed a tumor stretching from the cardia to the lesser curvature side of the high body.

The patient was referred to Cathay General Hospital for further evaluation. The levels of tumor markers CEA, CA19-9, and SCC were all within the normal range. Abdominal computed tomography (CT) revealed an irregular lobular mass, measuring approximately 7.5 $\times 6.5 \times 8.5 \mathrm{~cm} 3$, stretching from the esophagogastric junction (EGJ) to the lesser curvature of the gastric high body, with at least three enlarged regional lymph nodes around the EGJ and lesser curvature of the stomach (Figure 2A, 2B). Nevertheless, chest $C$ T revealed absence of pulmonary metastasis.

The patient subsequently received total gastrectomy with Roux-en-Y esophagojejunostomy (Figure 3).

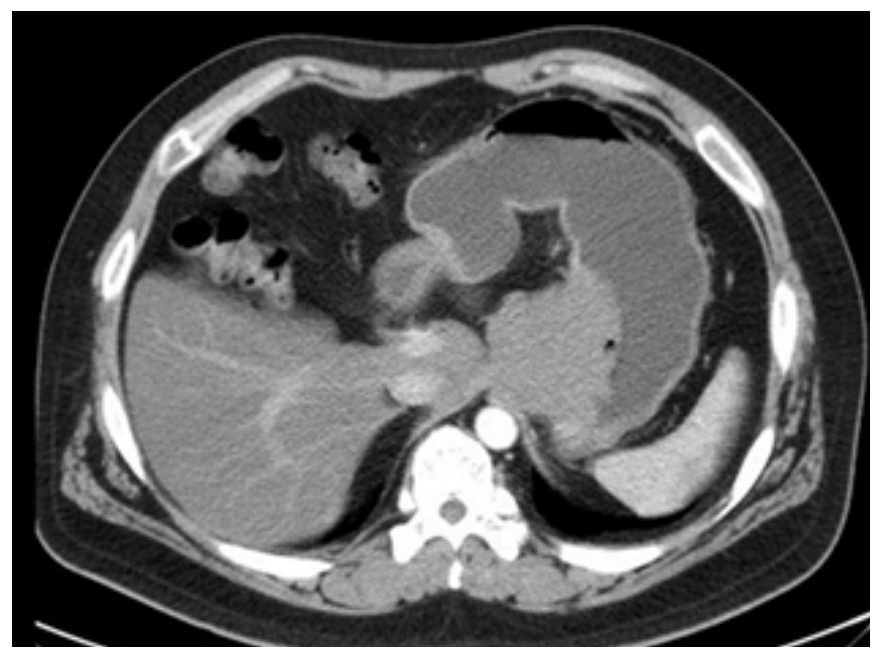

Figure 2A: Irregular lobular mass lesion stretching from the $E G J$ to the lesser curvature of the gastric high body.

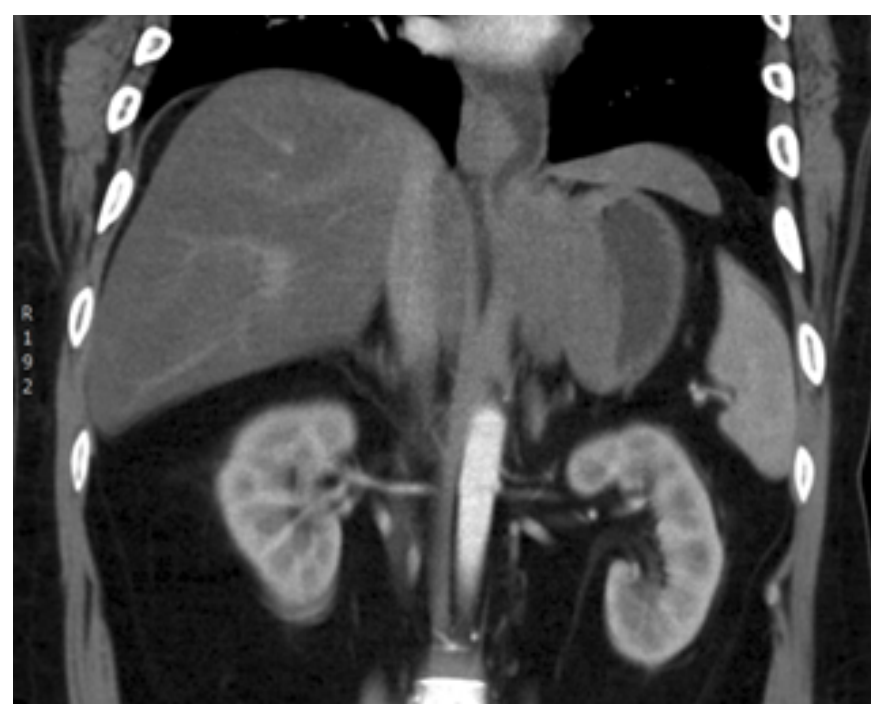

Figure 2B: A $3 \mathrm{~cm}$ submucosal mass at distal esophagus, suspect regional lymphadenopathy.

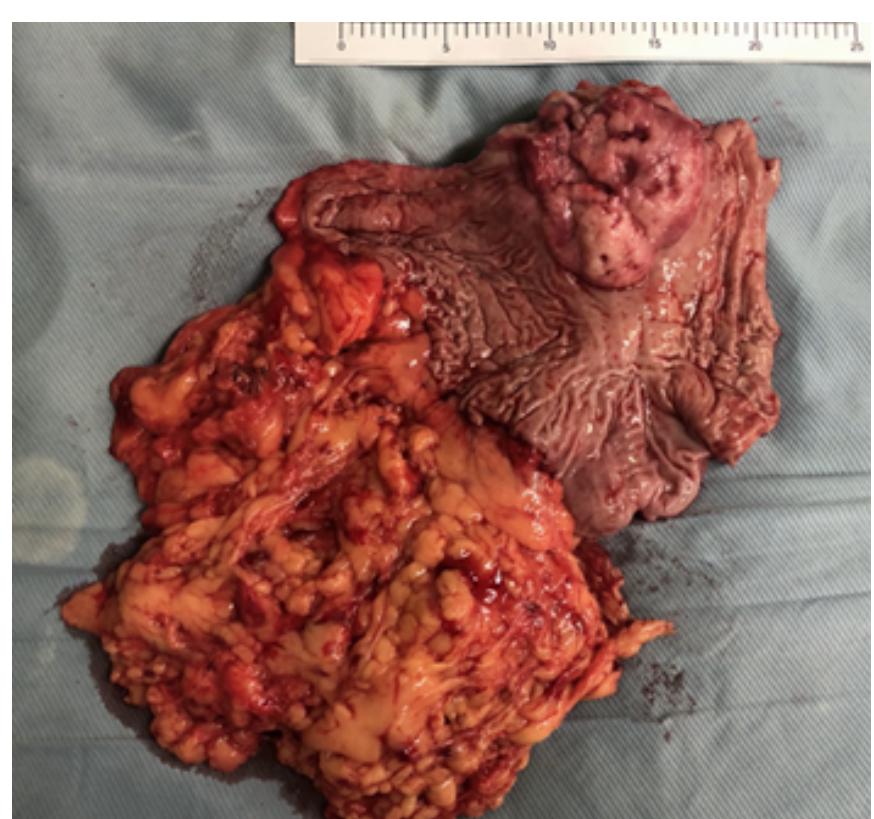

Figure 3: Polypoid tumor with central ulceration at the cardiac region 
Macroscopic examination of the excised tissue revealed an $11.2 \times 8.9 \mathrm{~cm} 2$ tumor mass, invading up until the serosa (Figure 4), but no lymph node metastasis was found. Histopathological examination revealed complex glandular formation with marked nuclear atypia and small, loose clusters of atypical cells, with indistinct to little eosinophilic cytoplasm and marked pleomorphic and hyperchromatic nuclei (Figure 5). Moreover, immunohistochemical analysis showed that the loose, atypical cells were positive for CK(AE1/3), myogenin, and desmin but negative for S-100, CD117, CD34, and CD45RB. Taken together, these results confirmed the diagnosis of gastric carcinosarcoma with rhabdomyosarcomatous differentiation, at a pathological stage of T4aNOM0 (Stage IIB).

Based on this diagnosis, the patient was administered six cycles of dacarbazine and doxorubicin for chemotherapy. Moreover, because the paraesophageal lymphadenopathy was inaccessible during surgery, the patient was also administered local radiotherapy, as suggested by our radiation oncologist.

Finally, owing to favorable recovery, the patient was discharged on the 14th postoperative day. At the 16-month follow-up, the patient did not show any evidence of recurrence.

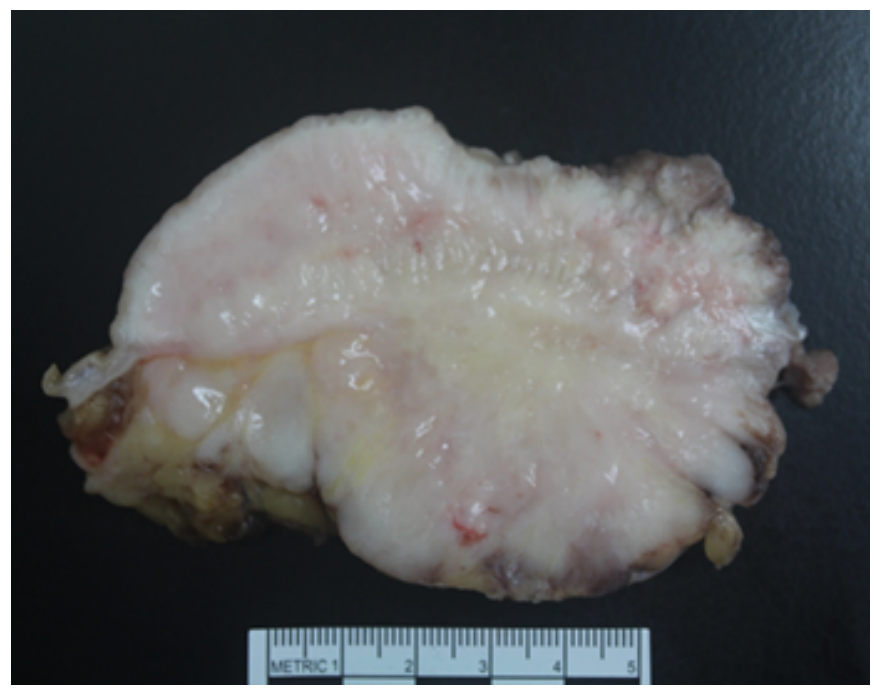

Figure 4: Tan-white and firm tumor invading from the mucosa to the serosa

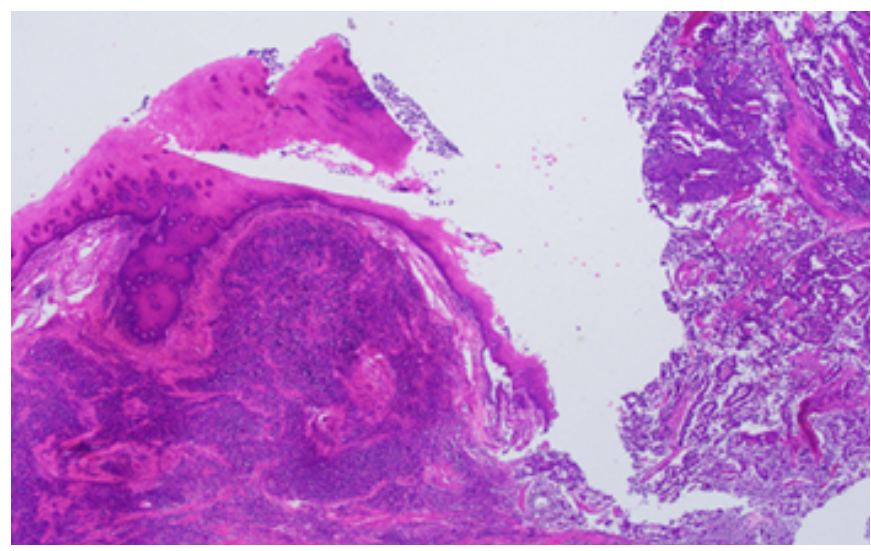

Figure 5A: Glandular structure and solid pattern.

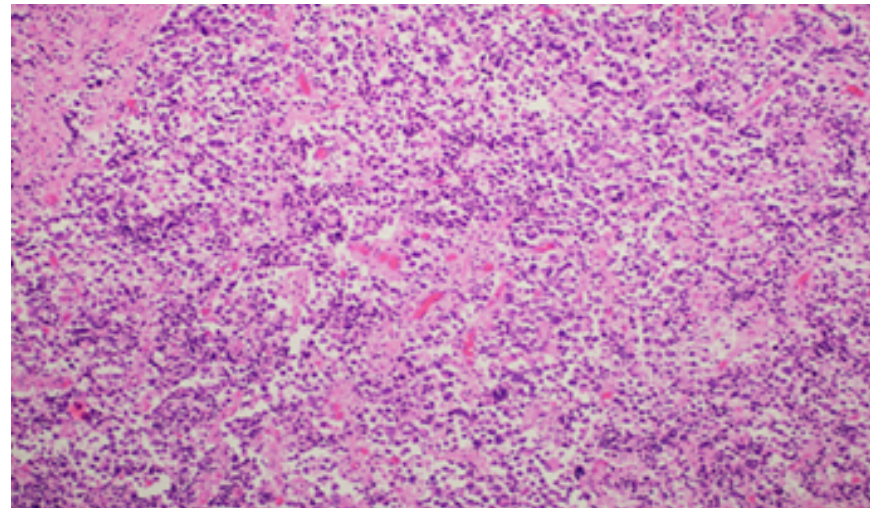

Figure 5B: Single neoplastic cells with marked pleomorphism.

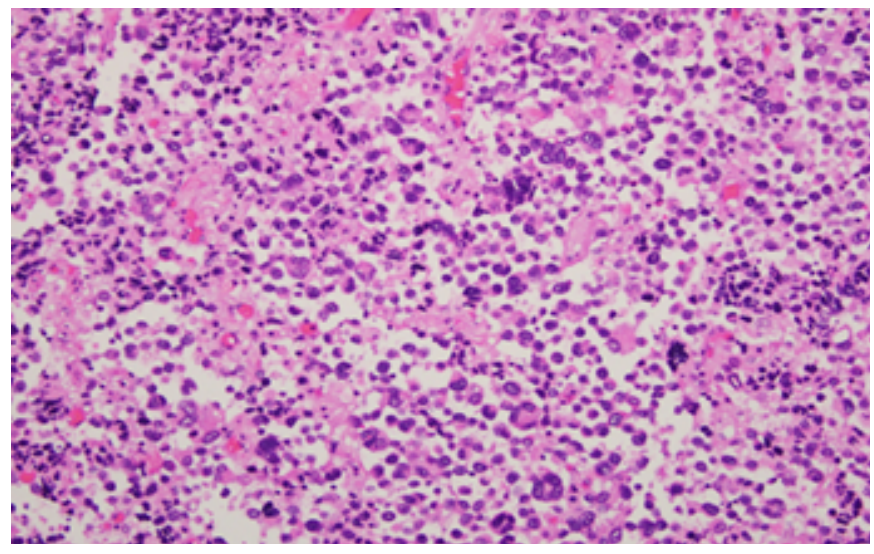

Figure 5C: Single neoplastic cells with marked pleomorphism, eosinophilic cytoplasm, and apoptosis.

\section{Discussion}

Based on the conventional histological findings, the World Health Organization defines carcinosarcoma as a malignant tumor composed of intimately mixed epithelial and mesenchymal elements of a type ordinarily found in malignancies of adults.[16] Carcinosarcoma can have a wide variety of localization sites, with the uterus being the most common site. However, as mentioned, localization in the stomach is rare. Table 1 presents various features of gastric carcinosarcoma with rhabdomyosarcomatous differentiation included in all 12 relevant cases reported thus far.[5-15]

In all 12 cases, no clinical feature was associated with age, sex, or location. However, polypoid lesions were the most commonly reported.[17] The tendency of gastric rhabdomyosarcoma to metastasize to the lymph node and lungs is consistent with the observations of rhabdomyosarcoma originating from other sites.

The current gold standard technique for definitive diagnosis is based on immunohistochemical staining of endoscopic biopsy or on surgical findings. Radical gastrectomy is the treatment of choice when feasible, even when the tumor shows rapid growth and malignant potential. The therapeutic effects of chemotherapy or radiotherapy have not been reported thus far. Moreover, given that this condition is rare and is diagnosed at advanced stage in most cases, no applicable standard chemotherapy regimen is available yet. 


\begin{tabular}{|c|c|c|c|c|c|c|}
\hline Author & Age/sex & Location & Size $(\mathrm{cm})$ & $\begin{array}{c}\text { Gross } \\
\text { Feature }\end{array}$ & $\begin{array}{l}\text { Depth of } \\
\text { invasion }\end{array}$ & Outcome \\
\hline Stout (1953) [8] & & & & & Submucosa & \\
\hline Kyogoku (1960) [4] & $49 / M$ & & & & & Dead, 36 mon \\
\hline $\begin{array}{c}\text { Matsukuma } \\
\text { (1977) [9] }\end{array}$ & $74 / M$ & $\begin{array}{l}\text { Remnant } \\
\text { Stomach }\end{array}$ & $15 \times 11$ & Polypoid & Serosa & Dead, 5 mon \\
\hline Machida (1981) [7] & $39 / F$ & Cardiac & $7 \times 6$ & Polypoid & Submucosa & Dead, 5 mon \\
\hline Fox $(1990)[10]$ & $68 / F$ & Body & $15 \times 10$ & Polypoid & Mucosa & Dead, 26 mon \\
\hline Sugai (1991) [11] & $78 / M$ & Pylorus & $9 \times 7$ & Polypoid & Serosa & Dead, 5 mon \\
\hline Melato (1993) [S] & $73 / \mathrm{M}$ & $\begin{array}{l}\text { Remnant } \\
\text { Stomach }\end{array}$ & $7 \times 5.5$ & Polypoid & Serosa & \\
\hline Nakayama (1997) [6] & $69 / M$ & $\begin{array}{l}\text { Remnant } \\
\text { Stomach }\end{array}$ & $20 \times 18$ & Polypoid & & \\
\hline $\begin{array}{c}\text { Tsuneyama (1999) } \\
\text { [12] }\end{array}$ & $63 / M$ & Pylorus & $7 \times 6.5$ & Polypoid & Subserosa & Alive, 10 mon \\
\hline Sato $Y(2001)[13]$ & $67 / F$ & Fundus & $8 \times 7$ & Polypoid & & Alive, 11 mon \\
\hline Fujiie (2016) [14] & $71 / \mathrm{F}$ & Body & $2 \times 1.5$ & Polypoid & Subserosa & Alive, 36 mon \\
\hline Tokuda (2019) [15] & $82 / \mathrm{M}$ & Body & $8 \times 8$ & Polypoid & Subserosa & Dead, 3 mon \\
\hline Our case & $34 / \mathrm{M}$ & Cardia & $11 \times 9$ & Polypoid & Serosa & Alive, 16 mon \\
\hline
\end{tabular}

Table 1: Reported cases of gastric carcinosarcoma with rhabdomyosarcomatous differentiation.

\section{Acknowledgements}

None

\section{Contributors}

HYS, CPL, FCT conceptualized and designed the study, acquired, and analyzed data, interpreted the study results, drafted the manuscript, and critically revised the final version of the manuscript.

\section{Funding}

No funding was received for this study.

\section{Competing interests}

No benefits in any form have been received or will be received from a commercial party related directly or indirectly to the subject of this article.

\section{Availability of data and materials}

Further information is available from the corresponding author on reasonable request.

\section{Ethics approval}

Not applicable.

\section{Provenance and peer review}

Not commissioned; externally peer reviewed.

\section{Open access}

This is an Open Access article distributed in accordance with the Creative Commons Attribution Non-Commercial (CC BY-NC 4.0) license, which permits others to distribute, remix, adapt, build upon this work noncommercially, and license their derivative works on different terms, provided the original work is properly cited and the use is non- commercial. See: http://creativecommons.org/licenses/ by-nc/4.0/

\section{References}

[1] Kanamoto A, Nakanishi Y, Ochiai A, Shimoda T, Yamaguchi H, Tachimori $Y$, et al. A case of small polypoid esophageal carcinoma with multidirectional differentiation, including neuroendocrine, squamous, ciliated glandular, and sarcomatous components. Arch Pathol Lab Med. 2000;124:1685-7.

[2] Yamazaki K. A gastric carcinosarcoma with neuroendocrine cell differentiation and undifferentiated spindle-shaped sarcoma component possibly progressing from the conventional tubular adenocarcinoma; an immunohistochemical and ultrastructural study. Virchows Arch. 2003;442:77-81.

[3] Insabato L, Di Vizio D, Ciancia G, Pettinato G, Tornillo L, Terracciano L. Malignant gastrointestinal leiomyosarcoma and gastrointestinal stromal tumor with prominent osteoclast-like giant cells. Arch Pathol Lab Med. 2004;128:440-3.

[4] Kyougoku M. An aotopsy case of carcinosarcoma which originated in the stomach. Gann. 1960;51:278-9.

[5] Melato M, Bucconi S, Grillo BP, Angelucci D, Di Stefano P, Natoli C. Carcinosarcoma and separate neuroendocrine malignant tumor of a malignancy promoter, the gastric stump. Anticancer Res. 1993;13:2485-8.

[6] Nakayama Y, Murayama H, Iwasaki H, Iwanaga S, Kikuchi M, Ikeda S, et al. Gastric carcinosarcoma (sarcomatoid carcinoma) with rhabdomyoblastic and osteoblastic differentiation. Pathol Int 1997;47:557-63.

[7] Machida T. A case of carcinosarcoma of the stomach. General No Rinsho. 1981;27:1763-8.

[8] Stout AP. Tumors of the stomach. In: Ackerman LV, Lattes R, editors Atlas of tumor pathology, section 6, fascicle 21 Washington DC: Armed Forces Institute of Pathology. 1953:98-9.

[9] Matsukuma S, Wada R, Hase K, Sakai Y, Ogata S, Kuwabara N. Gastric stump carcinosarcoma with rhabdomyosarcomatous differentiation. Pathol Int. 1997;47:73-7.

[10] Fox KR, Moussa SM, Mitre RJ, Zidar BL, Raves JJ. Clinical and pathologic features of primary gastric rhabdomyosarcoma. Cancer. 1990;66:772-8.

[11] Sugai T. A carcinosarcoma of the stomach. Jan J Cancer Clin. 1991;37:777-83.

[12] Tsuneyama K, Sasaki M, Sabit A, Yokoi K, Arano Y, Imai T, et al. A case report of gastric carcinosarcoma with rhabdomyosarcomatous and neuroendocrinal differentiation. Pathol Res Pract. 1999;195:93-7; 
discussion 8.

[13] Sato Y, Shimozono T, Kawano S, Toyoda K, Onoe K, Asada Y, et al. Gastric carcinosarcoma, coexistence of adenosquamous carcinoma and rhabdomyosarcoma: a case report. Histopathology. 2001;39:543-4.

[14] Fujiie M, Yamamoto M, Taguchi K, Iwanaga A, Ohgaki K, Egashira A, et al. Gastric carcinosarcoma with rhabdomyosarcomatous differentiation: a case report and review. Surg Case Rep. 2016;2:52.

[15] Tokuda K, Horiuchi A, Akehi S, Sakai K, Kitazawa S. True Gastric Carcinosarcoma with Rhabdomyosarcomatous Differentiation. The Japanese Journal of Gastroenterological Surgery. 2019;52:157-65.

[16] Maiorana A, Fante R, Maria Cesinaro A, Adriana Fano R. Synchronous occurrence of epithelial and stromal tumors in the stomach: a report of 6 cases. Arch Pathol Lab Med. 2000;124:682-6.

[17] Enzinger FM, Weiss SW. Soft tissue tumors. 2nd ed St Louis: Mosby. 1988;49:177-87. 